\title{
Swarna Prashana-an Ayurvedic Immunization
}

\author{
Rohit Mehta $V^{*}$ and Ashutosh Guleri \\ KAYAKALP (Himalayan Research Institute for Yoga \& Naturopathy), India
}

*Corresponding author: Rohit Mehta V, Senior Medical Officer, KAYAKALP (Himalayan Research Institute for Yoga \& Naturopathy), Vivekanand Medical Research Trust, Palampur, Kangra (HP), India

\section{Opinion}

A child is an asset \& hope not only for Parents and family but also for the whole nation as "Children of today are the citizens of tomorrow". Many infectious diseases and developmental disorders are prevailing among the children. Ayurvedic medicines are of greater value in combating and preventing many diseases of modern era. Swarna Prashana-a unique Ayurvedic way of boosting the immunity in newborn \& other children has been successfully practiced by different Institutions and many Ayurvedic practitioners throughout the country from the last 2 decades. It has improved the quality of life of children by showing marked improvement in the developmental milestones, IQ levels and immunity. It has been clinically observed that there was a marked decline in the recurrent attacks of respiratory, digestive and other systemic disorders. Not only infants but also children of age group between 10-16yrs have shown significant improvement in their day to day activities, performed well in exams, and so on.

Swarna prashana is a safe ayurvedic combination, prepared with pure Gold Bhasma and other special herbs. This is beneficial for growing children, who face strong need for improving their mental function along with physical strength and who want to be first at every step in today competitive life. This medicine is given on the day of Pushyami (Pushya) Nakshatra, every month to impart greater efficacy.

\section{Benefits}
A. Boost memory and enhances grasping power,
B. Increases attention and improves concentration,
C. Refines learning abilities,

D. Gives strong protection from infections and different kinds of allergies,

E. Helps in preventing diseases that occur during teething phase,

F. Protects from diseases that occur due to seasonal changes,

G. Improved physical development can be seen,

H. Improved sense of hearing, speech and visual ability,

I. Growth of mind and body becomes faster. Improves appetite,

J. Improve digestion Tones up skin color.

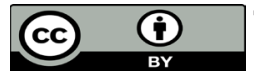

This work is licensed under Creative Commons Attribution 4.0 License

To Submit Your Article Click Here: Submit Article

DOI: $10.32474 /$ CTBM.2019.01.000118

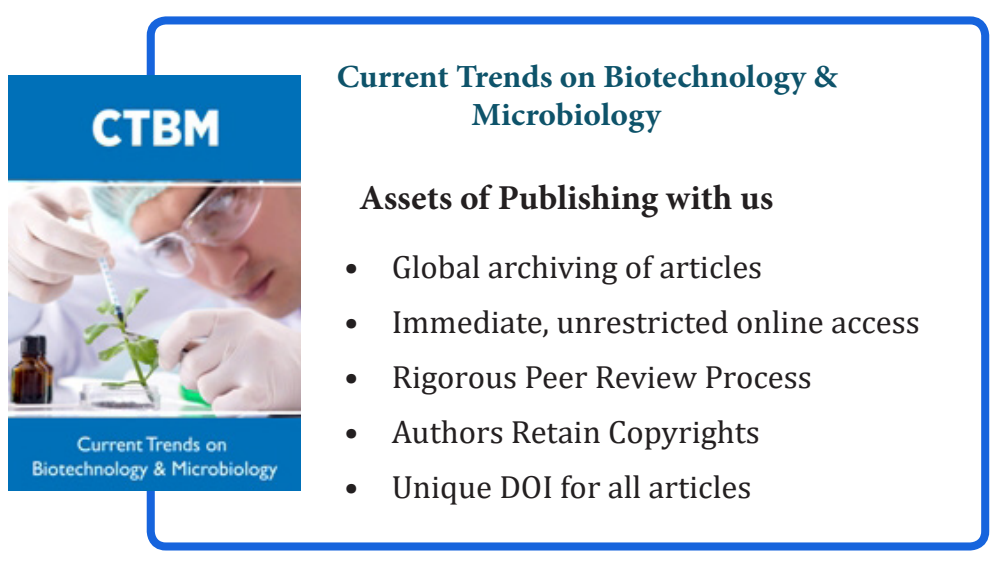

